\title{
Basics in hip chondrolabral lesions and state of the art
}

\author{
Mohamed Abd El-Radi ${ }^{1}$, Oliver R. Marin-Peña ${ }^{2, *}$, Hatem Galal Said ${ }^{1}$, and Marc Tey-Pons ${ }^{3}$ \\ 1 Orthopedic Surgery and Traumatology, University Hospital Assuit, Assiut, Egypt \\ 2 Orthopedic Surgery and Traumatology, University Hospital Infanta Leonor, Madrid, Spain \\ 3 Orthopedic Surgery and Traumatology, University Hospital del Mar, Barcelona, Spain
}

Received 20 March 2017, Accepted 11 July 2017, Published online 22 December 2017

\begin{abstract}
Chondrolabral complex is a weak point along an histological transition zone. Most cartilage and labral lesions in the femoroacetabular impingement syndrome are located in this area. Different classifications are used to evaluate the severity and predict the prognosis of chondrolabral complex injuries. Acetabular Labrum Articular Disruption (ALAD) and Multicenter Arthroscopy of the Hip Outcomes Research Network (MAHORN) classifications are commonly used with a prognosis and treatment implication. Treatment of chondrolabral lesions detected on magnetic resonance imaging (MRI), should only be considered when clinical symptoms are presented. A wide range of treatment options include debridement with or without microfracture, repair or regenerate therapies. The future of hip joint preservation should be directed towards to the development of the treatment of chondrolabral injuries.
\end{abstract}

Key words: Hip joint, Cartilage, Chondrolabral junction, Arthroscopy, Treatment options.

\section{Anatomy}

The hip joint is a deeply seated weight-bearing articulation and has an important concern with anatomical stresses in comparison with the shoulder joint. It contains cartilage of two forms: hyaline cartilage, from the union of osteochondral complexes developed in gestational life, and labral fibrocartilage [1-3]. The hip joint also contains the ligamentum teres, which has an early developmental role in formation of the articulation as well as a structural role [4-6]. A fibrocartilagenous tissue, named the labrum, is situated all around the bony acetabular rim and it adds to the stability and congruity of the joint. It has the remarkable role of providing a tight biological seal that protects the articular cartilage $[3,7,8]$.

The chondrolabral complex structure has an intrinsic weak point or a transition zone between the acetabular labrum and the acetabular articular cartilage, especially in the anterior segment (Figure 1) [9].

\section{Pathophysiology}

In normal hips, the acetabular labrum fuses with the articular cartilage of the acetabular side through the transition zone smoothly without any defects [10]. One reason for

\footnotetext{
*Corresponding author: olivermarin@yahoo.es
}

chondrolabral junction injuries affecting adults is the impingement syndrome. Femoroacetabular impingement (FAI) has two types, which are cam type and pincer type. The cam type impingement is encountered in the pathomechanical analysis of injury to the chondrolabral complex and is produced by a primary osseous variant of the head-neck junction at the femoral head epiphyseal line, but it can be secondary to several known causes, such as Perthes disease, epiphyseal slipping of the femoral head, or following fractures of the femoral neck; it might be considered as an idiopathic entity [11-13]. In the cam type impingement, the articular cartilage of the acetabulum is affected anterosuperiorly. The labrum is attached firmly to the underlying bone, but the articular cartilage is peeled from the labrum at this weak point of transition [14] (Figure 2). The main problem in the cam FAI type is the absence of a waist area at the femoral head-neck junction. In flexion phases, this part is compressed against the acetabulum anterosuperiorly and this generates shear force at that transition point and in subchondral bone. This causes the labrum to be stretched and pushed laterally, and the cartilage is pushed centrally [15]. In hips with the pincer type, the cartilage is usually affected circumferentially and that causes damage to the acetabular cartilage at its anterosuperior junctional margin. In that situation, the generated force causes the labrum to be compressed between the femoral head at one side and underlying bone at the other side which limits the predicted injury at the rim zone of the acetabular cartilage [14]. 


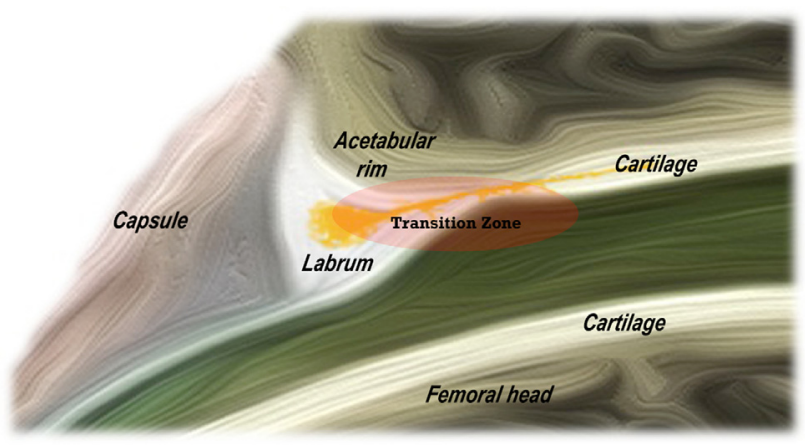

Figure 1. Diagram showing the transition zone of chondrolabral complex.

\section{Classifications}

Different classification systems assess the severity and predict the prognosis of chondrolabral complex injuries.

Beck's Classification [16]:

- Malacia: roughening of surface, fibrillation.

- Debonding: loss of fixation to the subchondral bone, carpet phenomenon.

- Cleavage: loss of fixation to the subchondral bone, frayed edges, cartilage thinning, flap.

- Defect: complete thickness defect.

\section{MAHORN Classification [17] (Figure 3):}

- Bubble: this is a palpable bulkiness to the articular cartilage at the periphery. This lesion probably represents

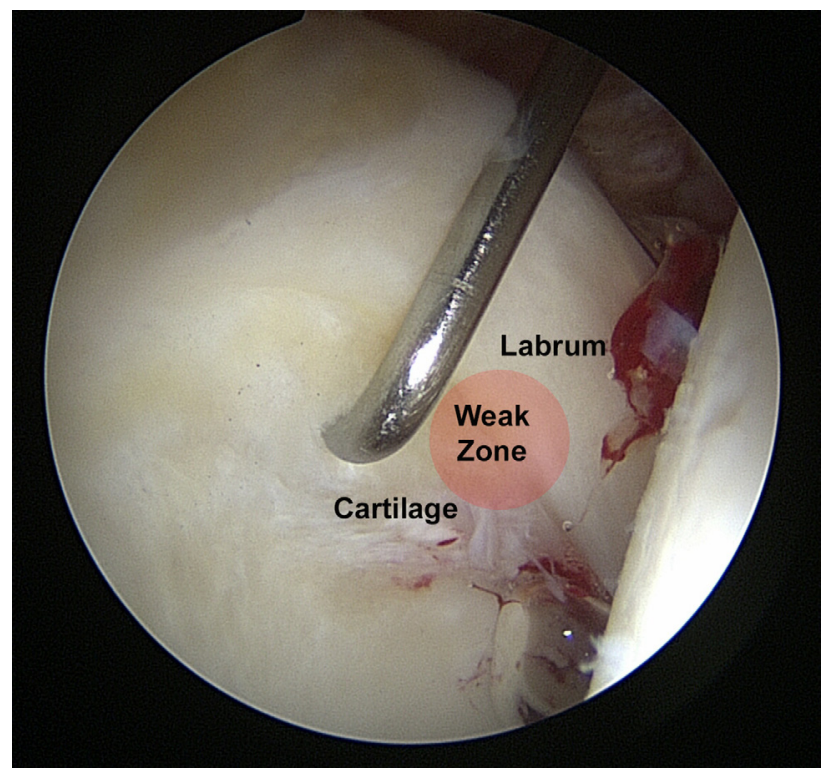

Figure 2. Damage of the chondrolabral transition ("weak zone") in a cam FAI.

delamination of the articular cartilage and is sometimes referred to as "wave sign".

- Chondrolabral separation: shearing forces cause chondrolabral separation at its junctional zone.

- Pocket: when the delamination of a bubble connects to a chondrolabral separation tear, a pocket is formed.

- Flap: once the pocket becomes unstable. It is the commonest finding in the arthroscopy of cam-type femoroacetabular impingement.

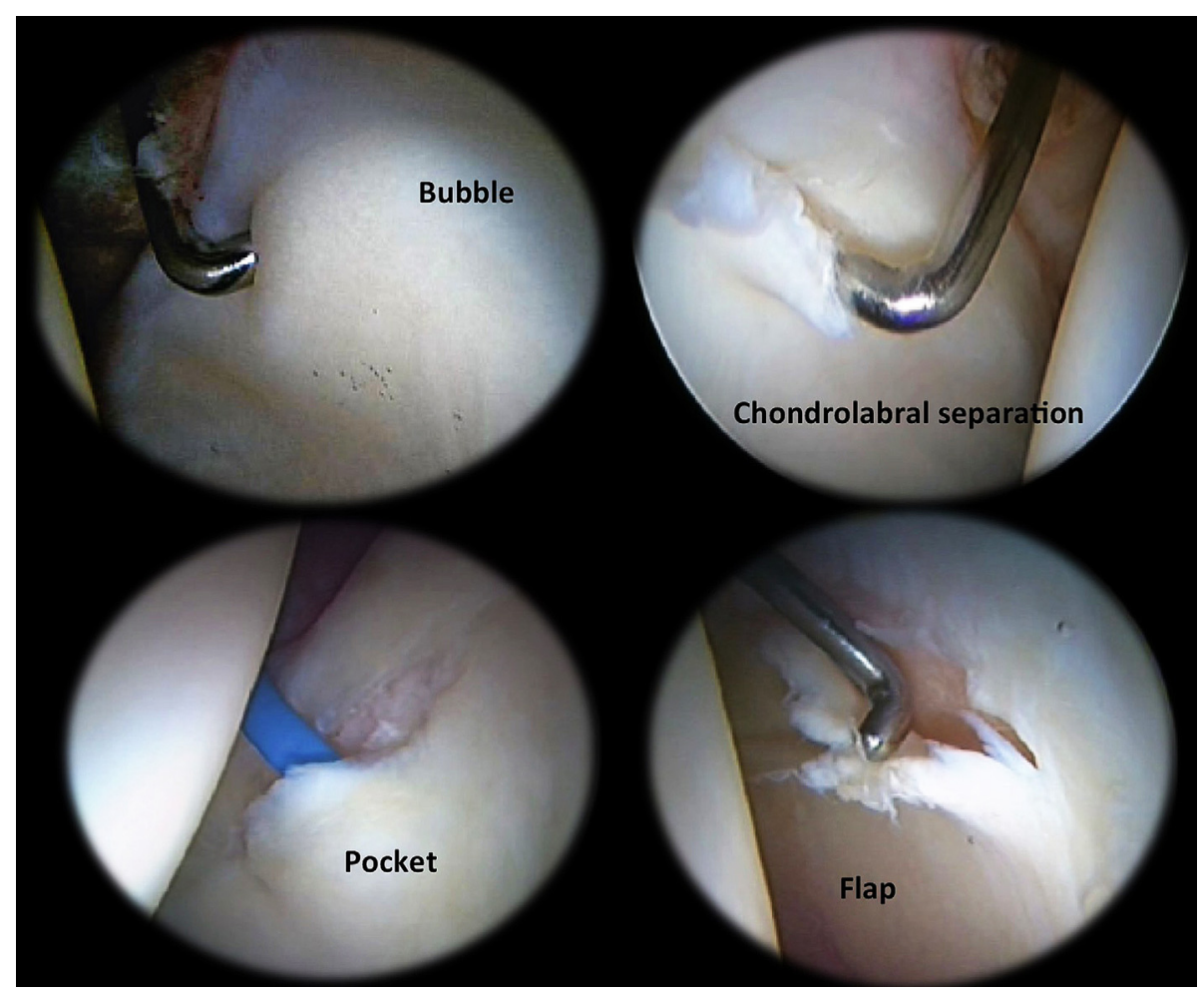

Figure 3. MAHORN classification. Bubble (upper left), separation (upper right), pocket (bottom left), flap (bottom right). 


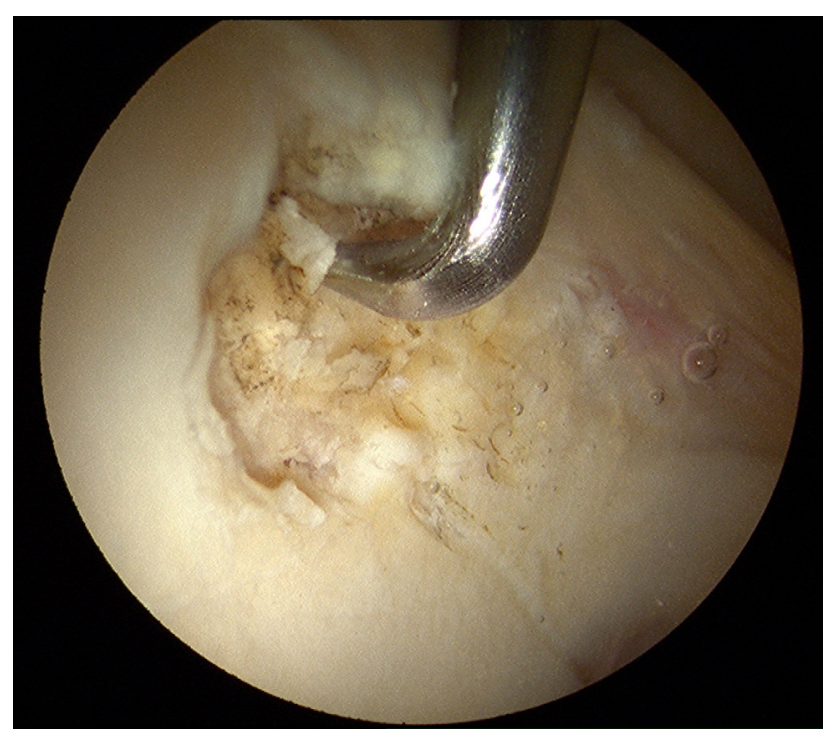

Figure 4. Cartilage lesion ALAD 4 treated with debridement and stabilization of the borders together with microfracturing.

- Defect: the final step is loss of the flap by disintegration or detachment.

Acetabular Labrum Articular Disruption (ALAD) Classification [18]:

- ALAD 1: softening of the adjacent cartilage.

- ALAD 2: early peel of the cartilage (carpet delamination).

- ALAD 3: large flap of the cartilage.

- ALAD 4: loss of cartilage.

If we compare ALAD and MAHORN classifications, lesion type ALAD 2 could be similar to a "bubble" in the MAHORN classification (Figure 3). Otherwise, ALAD 3 cartilage injury correlates with flap lesion in MAHORN (Figure 4).

\section{Treatment options}

Treatment of such injuries detected on MRI, should only be considered when clinical symptoms are present. Clinical symptoms and signs of chondrolabral lesions are variable. Femoroacetabular lesions usually present with ill-defined groin pain on the affected side $[19,20]$. This pain is related directly to mechanical situations especially with flexion and internal rotation [14]. Correct imaging techniques ensure the exact extent of the chondrolabral lesion is seen. Treatment of chondrolabral injuries is dependent on the time of patient presentation. The gold standard treatment of an arthritic hip is total joint replacement [21-23]. Recently, many articular cartilage strategies have been tried to restore focal and diffuse damage in the active patient (Figure 5). The use of microfracture techniques is described to restore focal articular cartilage defects through stimulation of inner pelvic wall stem cells [23-26]. The replacement cartilage in these defects is found to have some characteristics of the hyaline cartilage [25]. Philippon et al. [27] evaluated, through a second look hip arthroscopy, the filling percentage of chondral defects following the microfracture procedure at the acetabular side in the nine patients. They reported the percentage of filling as high as $95-100 \%$ in injuries at a mean of 20-month follow-up [27]. Domb et al. [28] examined the clinical improvement in a cohort study looking at the patient reported outcome at twoyear follow-up. They demonstrated excellent results after the microfracture technique. McDonald et al. [24] and Fontana et al. [29] reported that athletes competing at high level, returned to their previous level of activity after they were treated by the microfracture technique. Cartilage regeneration techniques were studied by Fontana et al. [29]. They documented the comparison between autologous chondrocyte transplantation and simple debridement in an equal number of patients with chondral defect of grade three or four of Outerbridge classification at the acetabular articular cartilage. They demonstrated an improved clinical outcome in chondrocyte transplantation patients at 74 months postoperatively in comparison to the other group.

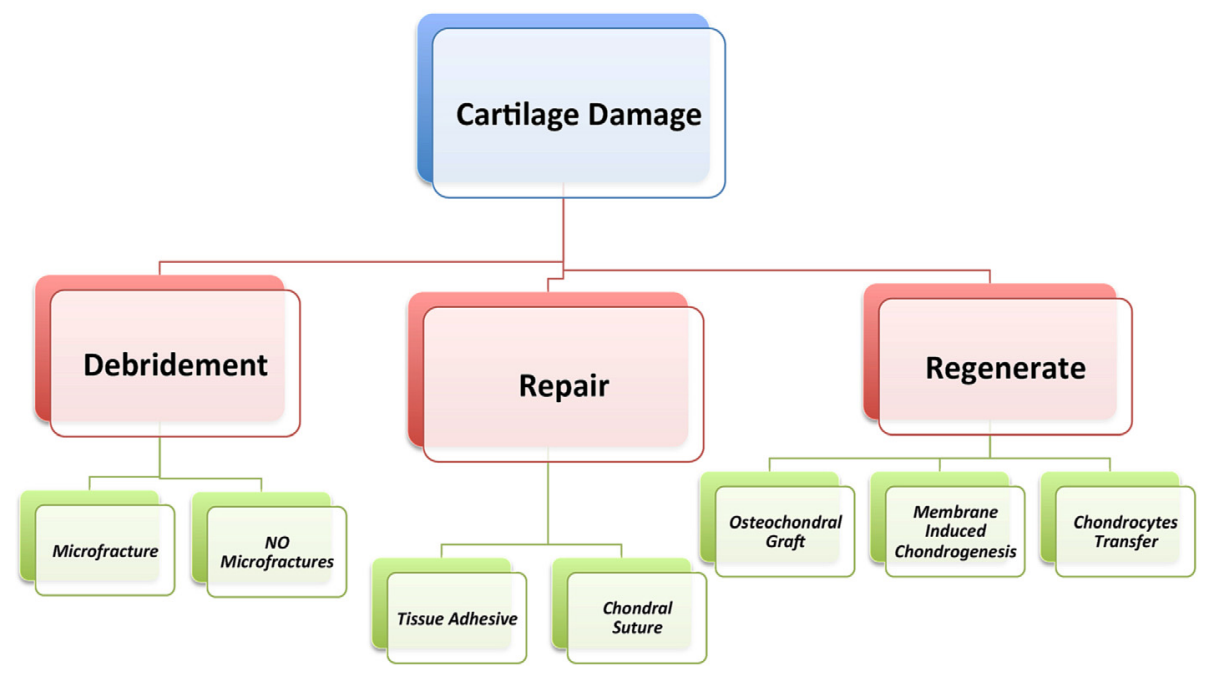

Figure 5. Chondrolabral lesions management. 


\section{Conclusions}

Chondrolabral injuries continue to be a challenge for hip arthroscopists. Nevertheless, many new treatment alternatives have been developing in the last few years and clinical results of these techniques will be published in the following decade. The future of hip joint preservation should be improved by the further development of the treatment of chondrolabral injuries.

\section{Conflict of interest}

The authors declare that they have no conflict of interest in relation with this paper.

\section{References}

1. Bharam S (2006) Labral tears, extra-articular injuries, and hip arthroscopy in the athlete. Clin Sports Med 25(2), 279-292.

2. Groh MM, Herrera J (2009) A comprehensive review of hip labral tears. Curr Rev Musculoskelet Med 2(2), 105-117.

3. Kalhor M, Horowitz K, Beck M, Nazparvar B, Ganz R (2010) Vascular supply to the acetabular labrum. J Bone Joint Surg Am 92(15), 2570-2575.

4. Hosalkar HS, Varley ES, Glaser D, Farnsworth CL, Bomar JD, Wenger DR (2011) Isocentric reattachment of ligamentum teres: a porcine study. J Pediatr Orthop 31(8), 847-852.

5. Phillips M, Philippon MJ, Letkemann S, Simunovic N, Ayeni OR (2014) Ligamentum teres injuries of the hip: a systematic review examining surgical indications, treatment options, and outcomes. Arthroscopy 30(12), 1634-1641.

6. Simpson JM, Field RE, Villar RN (2011) Arthroscopic reconstruction of the ligamentum teres. Arthroscopy 27(3), 436-441.

7. Ferguson S, Bryant J, Ganz R, Ito K (2000) The influence of the acetabular labrum on hip joint cartilage consolidation: a poroelastic finite element model. J Biomech 33(8), 953-960.

8. Ferguson S, Bryant J, Ganz R, Ito K (2000) The acetabular labrum seal: a poroelastic finite element model. Clin Biomech 15(6), 463-468.

9. Field RE, Rajakulendran K (2011) The labro-acetabular complex. J Bone Joint Surg Am 93(Supplement 2), 22-27.

10. Seldes RM, Tan V, Hunt J, Katz M, Winiarsky R, Fitzgerald RH Jr. (2001) Anatomy, histologic features, and vascularity of the adult acetabular labrum. Clin Orthop Relat Res 382, 232-240.

11. Leunig M, Casillas MM, Hamlet M, Hersche O, Nötzli H, Slongo T (2000) Slipped capital femoral epiphysis: early mechanical damage to the acetabular cartilage by a prominent femoral metaphysis. Acta Orthop Scand 71(4), 370-375.

12. Snow SW, Keret D, Scarangella S, Bowen JR (1993) Anterior impingement of the femoral head: a late phenomenon of LeggCalve-Perthes' disease. J Pediatr Orthop 13(3), 286-289.

13. Strehl A, Ganz R (2005) Anterior femoroacetabular impingement after healed femoral neck fractures. Unfallchirurg 108(4), 263-273.
14. Beck M, Kalhor M, Leunig M, Ganz R (2005) Hip morphology influences the pattern of damage to the acetabular cartilage. J Bone Joint Surg Br 87(7), 1012-1018.

15. Beck M, Chegini S, Ferguson S, Hosalkar HS (2012) Mechanism of femoroacetabular impingement, in Femoroacetabular Impingement. Marín-Peña Ó, Editor. Berlin, Heidelberg, Springer-Verlag.

16. Beck M, Leunig M, Parvizi J, Boutier V, Wyss D, Ganz R (2004) Anterior femoroacetabular impingement: part II. Midterm results of surgical treatment. Clin Orthop Relat Res 418, 67-73.

17. Moreno N, Marín-Peña Ó (2012) Clinical Scores in Femoroacetabular Impingement, in Femoroacetabular Impingement. Marín-Peña Ó, Editor. Berlin, Heidelberg, Springer-Verlag.

18. Callaghan JJ, Rosenberg AG, Rubash HE (2007) The adult hip. Philadelphia, Lippincott Williams \& Wilkins.

19. Clohisy JC, Knaus ER, Hunt DM, Lesher JM, Harris-Hayes M, Prather H (2009) Clinical presentation of patients with symptomatic anterior hip impingement. Clin Orthop Relat Res 467(3), 638-644.

20. Dooley PJ (2008) Femoroacetabular impingement syndrome Nonarthritic hip pain in young adults. Can Fam Physician 54(1), 42-47.

21. Domb BG, Gui C, Lodhia $P$ (2015) How much arthritis is too much for hip arthroscopy: a systematic review. Arthroscopy 31(3), 520-529.

22. Philippon MJ, Briggs KK, Carlisle JC, Patterson DC (2013) Joint space predicts THA after hip arthroscopy in patients 50 years and older. Clin Orthop Relat Res 471(8), 2492-2496.

23. Philippon MJ, e Souza BGS, Briggs KK (2012) Hip arthroscopy for femoroacetabular impingement in patients aged 50 years or older. Arthroscopy 28(1), 59-65.

24. McDonald JE, Herzog MM, Philippon MJ (2013) Return to play after hip arthroscopy with microfracture in elite athletes. Arthroscopy 29(2), 330-335.

25. Frisbie DD, Oxford JT, Southwood L, Trotter GW, Rodkey WG, Steadman JR (2003) Early events in cartilage repair after subchondral bone microfracture. Clin Orthop Relat Res 407, 215-227.

26. Frisbie DD, Morisset S, Ho CP, Rodkey WG, Steadman JR, Mcllwraith CW (2006) Effects of calcified cartilage on healing of chondral defects treated with microfracture in horses. Am J Sports Med 34(11), 1824-1831.

27. Philippon MJ, Schenker ML, Briggs KK, Maxwell RB (2008) Can microfracture produce repair tissue in acetabular chondral defects? Arthroscopy 24(1), 46-50.

28. Domb BG, El Bitar YF, Lindner D, Jackson TJ, Stake CE (2014) Arthroscopic hip surgery with a microfracture procedure of the hip: clinical outcomes with two-year follow-up. Hip Int 24(5), 448-456.

29. Fontana A, Bistolfi A, Crova M, Rosso F, Massazza G (2012) Arthroscopic treatment of hip chondral defects: autologous chondrocyte transplantation versus simple debridement - a pilot study. Arthroscopy 28(3), 322-329. 